\title{
JENIS KESALAHAN SISWA DALAM MENYELESAIKAN SOAL PERSAMAAN NILAI MUTLAK LINIER SATU VARIABEL
}

\author{
Oktra Okta Saktiawan ${ }^{1}$, Della Maulidiya ${ }^{2}$, dan Teddy Alfra Siagian. ${ }^{3}$ \\ ${ }^{1,2,3}$ Program Studi Pendidikan Matematika, JPMIPA FKIP Universitas Bengkulu \\ Email : ${ }^{1}$ oktraoo@gmail.com, ${ }^{2}$ della.maulidiya@unib.ac.id, ${ }^{3}$ teddysiagian@unib.ac.id
}

\begin{abstract}
Abstrak
Tujuan dari penelitian ini untuk menganalisis jenis-jenis kesalahan yang dilakukan siswa dan dalam menyelesaikan soal persamaan nilai mutlak linier satu variabel. Jenis penelitian ini adalah penelitian deskriptif. Instrumen penelitian berupa tes diagnostik dan wawancara. Sampel dalam penelitian ini adalah kelas X MIA 3 SMA N 3 Kota Bengkulu yang berjumlah 33 siswa. Setelah memberikan tes diagnostik, peneliti melakukan wawancara terhadap siswa yang melakukan kesalahan dalam menyelesaikan soal tes diagnostik. 1) Kesalahan siswa dalam menyelesaikan soal tentang nilai variabel persamaan mutlak $|\mathrm{x}-\mathrm{a}|=\mathrm{b}$ dan $\left|\mathrm{x}-\frac{a}{b}\right|=\frac{c}{d}$ dilakukan oleh 26 siswa dengan 22 kesalahan konsep dan 7 kesalahan operasi; 2) Kesalahan siswa dalam menyelesaikan soal tentang nilai variabel persamaan mutlak $|\mathrm{ax}+\mathrm{b}|=\mathrm{c}$ dan $\left|\frac{a}{b} \mathrm{x}-\mathrm{c}\right|=\mathrm{d}$ dilakukan oleh 26 siswa dengan 21 kesalahan konsep dan 12 kesalahan operasi; 3) Kesalahan siswa dalam menyelesaikan soal tentang nilai variabel persamaan mutlak a $|\mathrm{bx}-\mathrm{c}|+\mathrm{d}=\mathrm{e}$ dan a $\left|\frac{b}{c} \mathrm{x}-\frac{d}{e}\right|+\mathrm{f}=\mathrm{g}$ dilakukan oleh 29 siswa dengan 27 kesalahan konsep dan 13 kesalahan operasi; 4) Kesalahan siswa dalam menyelesaikan soal tentang nilai variabel persamaan mutlak $|\mathrm{ax}-\mathrm{b}|=|\mathrm{c}-\mathrm{x}|$ dan $\frac{|a x+b|}{|x-c|}=\mathrm{d}$ dilakukan oleh 24 siswa dengan 9 kesalahan fakta, 14 kesalahan konsep ,16 kesalahan operasi, 24 kesalahan prinsip.
\end{abstract}

Kata Kunci : Penelitian Deskriptif, Analisis Kesalahan Siswa, Persamaan Nilai Mutlak Linier Satu Variabel.

\begin{abstract}
The aims of this research were to analyze the types of error and factors affect the error made by the students in solving the problems of linear absolute value equations of single variable. This research was a descriptive research..The research instruments were diagnostic test and interview. The sample of this research were 33 students of class X MIA 3 SMA N 3 Bengkulu City. After giving diagnostic tests, researcher conducted interviews with students who made errors in resolved diagnostic tests. 1) students' error in solving problems about linear absolute value equations $|x-a|=b$ dan $\left|x-\frac{a}{b}\right|=\frac{c}{d}$ done by 26 students with 22 misconceptions and 7 errors operation; 2) students' error in solving the problems about linear absolute value equations $|a x+b|=c d a n\left|\frac{a}{b} x-c\right|=d$ done by 26 students with 21 misconceptions and 12 errors operation; 3) students' error in solving the problems about linear absolute value equations $a|b x-c|+d=$ edana $\left|\frac{b}{c} x-\frac{d}{e}\right|+f=g$ done by 29 students with 27 misconceptions and 13 errors operation; 4) students' error in solving the problems about linear absolute value equations $|a x-b|=|c-x|$ dan $\frac{|a x+b|}{|x-c|}=d$ done by 24 students with 9 errors fact, 14 misconceptions and 16 errors operation and 21 principle errors.
\end{abstract}

Keywords: Descriptive Research, Student Error Analysis, Linear Absolute Value Equations of Single Variable 


\section{PENDAHULUAN}

Materi pada pembelajaran matematika SMA memiliki tingkat kesulitan yang lebih tinggi dibandingkan materi yang ada di SMP dan SD.. Materi yang dipelajari di SMA salah satunya yaitu materi persamaan nilai mutlak linier satu variabel. Persamaan nilai mutlak linier satu variabel adalah materi yang mempelajari mengenai penjumlahan, pengurangan, pembagian dan perkalian bilangan bervariabel. Saat melakukan observasi di SMA N 3 tanggal 8 September 2016 peneliti mendapati bahwa masih banyak siswa yang melakukan kesalahan dalam menyelesaikan soal persamaan nilai mutlak linier satu variabel. Menurut keterangan dari guru matematika di SMA N 3 yaitu Ibu Yeni Handayani dan Ibu Lilis Suryani, S.Pd masih banyak siswa yang kesulitan dalam menjawab soal persamaan nilai mutlak linier satu variabel.

Dalam proses pembelajaran matematika ada yang namanya hasil belajar. Hasil belajar ini dapat diketahui dengan melakukan tes hasil belajar. Hasil belajar yang rendah merupakan salah satu bukti adanya kesalahan dalam menyelesaikan soal, guru dalam hal ini bertugas untuk memahami kesalahan siswa dalam menyelesaikan soal dan kemudian memberikan bantuan pemecahannya. Sehingga kesulitan siswa dalam menyelesaikan soal dapat terpecahkan dan hasil belajar siswa dapat meningkat.

\section{METODE PENELITIAN}

Jenis penelitian ini adalah penelitian deskriptif. Penelitian deskriptif (descriptive research) adalah penelitian yang dilakukan
Saat melakukan observasi di SMA N 3 tanggal 10 september 2016 peneliti menemukan bahwa pada siswa kelas 10 masih banyak yang kesulitan dalam menyelesaikan soal persamaan nilai mutlak linier satu variabel. Ini dibuktikan dari hasil belajar mereka yang masih rendah, berikut adalah rata-rata hasil belajar siswa kelas 10 SMA N 3 dalam materi persamaan nilai mutlak linier satu variabel.

Tabel 1. Rata-rata Nilai Siswa

\begin{tabular}{|c|c|}
\hline Kelas & Rata-rata \\
\hline X MIA 3 & 5,3 \\
\hline X MIA 5 & 4,9 \\
\hline
\end{tabular}

Dari tabel diatas dapat dilihat nilai ratarata siswa belum mencapai ketuntasan kriteria maksimum (KKM) yaitu sebesar 7,5, dari hal tersebut belum ada solusi penyelesaian masalah yang dilakukan oleh guru matematika di SMAN 3 Kota Bengkulu. Hal ini karena letak kesalahan-kesalahan yang dilakukan siswa dan faktor-faktor penyebab kesalahan siswa dalam menyelesaikan soal persamaan nilai mutlak linier satu variabel belum dianalisis oleh guru. Maka dari itu harus dilakukan upaya mengidentifikasi kesulitan siswa dan faktor penyebabnya agar guru dapat melakukan suatu tindakan untuk mengatasi kesulitan siswa sehingga tidak terjadi kesalahan yang sama pada pembelajaran selanjutnya.

untuk menggambarkan atau menjelaskan secara sistematis, faktual, dan akurat mengenai fakta dan sifat populasi tertentu (Sanjaya, 2013 : 59). Fakta yang dikaji

Oktra Okta Saktiawan, Della Maulidiya, Teddy Alfra Siagian 
dalam penelitian ini adalah kesalahankesalahan dan faktor-faktor penyebab kesalahan siswa dalam menyelesaikan soalsoal persamaan nilai mutlak linier satu variabel.

\section{a. Sasaran Penelitian}

Subjek dari penelitian ini adalah siswa kelas X MIA 3 dengan jumlah siswa sebanyak 33 orang diantaranya 8 orang siswa laki-laki dan 23 siswa perempuan di SMA N 3 Kota Bengkulu tahun ajaran 2016/2017. Peneliti memilih siswa kelas X MIA 3 sebagai subjek penelitian karena berdasarkan nilai rata-rata hasil belajar yang relatif rendah dan atas saran guru.

\section{b. Prosedur Penelitian}

Prosedur yang digunakan dalam penelitian ini adalah prosedur dalam membuat tes diagnostik yang bertujuan untuk mendiagnosis kesalahan-kesalahan siswa dalam menyelesaikan soal bilangan bervariabel atau persamaan nilai mutlak linier satu variabel. Adapun prosedur penelitian akan dilaksanakan menurut Mardapi (2012:110) adalah sebagai berikut : 1) Menyusun spesifikasi tes; 2) Menulis soal tes; 3) Menelaah soal tes; 4) Melakukan uji coba soal tes; 5) Menganalisis butir soal tes; 6) Memperbaiki tes; 7)Merakit tes; 8) Melaksanakan tes; 9) Menganalisis hasil tes.

\section{c. Instrumen Penelitian}

Dalam melakukan penelitian diperlukan pula instrumen pendukung untuk mengumpulkan datanya. Instrumen yang digunakan dalam penelitian ini adalah lembar tes dan lembar wawancara.

1. Lembar Tes

Mardapi (2012:108) menyatakan" tes merupakan salah satu bentuk instrumen yang digunakan untuk melakukan pengukuran dengan tujuan mengetahui pencapaian belajar atau kompetensi yang telah dicapai peserta didik untuk bidang tertentu". Jadi lembar tes adalah instrumen yang digunakan untuk mengukur tingkat pengetahuan dan kemampuan siswa dalam menyelesaikan tes dari materi yang diajarkan.

2. Lembar Wawancara

Lembar wawancara diperlukan untuk mengetahui apa yang menyebabkan siswa salah atau kesulitan dalam menyelesaikan soal tes yang diberikan. Wawancara dilakukan agar didapat data yang lebih akurat mengenai hal-hal yang menyebabkan siswa salah atau kesulitan dalam menyelesaikan soal dan agar data yang didapatkan tidak didapat dari satu pihak saja.

\section{d. Teknik Pengumpulan Data .}

Pada penelitian ini teknik pengumpulan data dilakukan dengan menggunakan metode sebagai berikut :

1. Tes

Tes yang digunakan pada penelitian ini adalah tes uraian yang bertujuan untuk mengidentifikasi dan menganalisis kesulitan dan kesalahan siswa.

\section{Wawancara}

Sudjana (2011: 68) menyatakan sebagai alat penilaian, wawancara dapat digunakan untuk menilai hasil dan proses belajar.

\section{e. Teknik Analisis Data}

\section{e.1. Analisis instrumen}

1. Validitas

Menurut (Mardapi, 2012:37) validitas merupakan dukungan bukti dan teori terhadap penafsiran skor tes dengan tujuan penggunaan tes. Jika data yang dihasilkan dari sebuah 
instrumen valid, maka dapat dikatakan bahwa instrumen tersebut valid, karena dapat memberikan gambaran tentang data secara benar sesuai dengan kenyataan atau keadaan sesunguhnya. Rumus yang digunakan untuk menghitung kevalidan tes yaitu :

$$
r_{x y}=\frac{N \sum X Y-\left(\sum X\right)\left(\sum Y\right)}{\sqrt{\left\{N \sum X^{2}-\left(\sum X\right)^{2}\right\}\left\{N \sum Y^{2}-\left(\sum Y\right)^{2}\right\}}}
$$

Keterangan :

$r_{x y}=$ koefisien korelasi antara variabel $\mathrm{X}$ dan $\mathrm{Y}$, dua variabel yang dikorelasikan

$N \quad=$ jumlah peserta tes

$X \quad=$ skor tiap item

$Y \quad=$ skor total

$\sum X=$ jumlah skor tiap item

$\sum Y=$ jumlah skor total

$\sum X Y=$ jumlah skor perkalian $\mathrm{X}$ dan $\mathrm{Y}$ (Arikunto, $2013: 87$ )

\section{Reliabilitas}

Reliabilitas merupakan koefisien yang menunjukkan tingkat keajengan atau konsistensi hasil pengukuran suatu tes (Mardapi, 2012:51). Untuk mengukur tingkat keajegan soal ini digunakan perhitungan Alpha Cronbach sebagai berikut:

$$
r_{11}=\left(\frac{n}{(n-1)}\right)\left(1-\frac{\sum \sigma_{i}^{2}}{\sigma_{t}^{2}}\right)
$$

Keterangan :

$r_{11}=$ Reliabilitas yang dicari

$n \quad=$ banyaknya butir soal

$\sum \sigma_{i}^{2} \quad=$ jumlah varians skor tiap-tiap butir soal

$\sigma_{t}^{2} \quad=$ varians total

(Arikunto, $2013:$ 122)

\section{Tabel 2. Kriteria Reliabilitas}

\begin{tabular}{|c|l|}
\hline Rentang Nilai & Kriteria \\
\hline$r_{11} \leq 0,20$ & Sangat Rendah \\
\hline $0,20<r_{11} \leq 0,40$ & Rendah \\
\hline $0,40<r_{11} \leq 0,70$ & Sedang \\
\hline $0,70<r_{11} \leq 0,90$ & Tinggi \\
\hline $0,90<r_{11} \leq 1,00$ & Sangat Tinggi \\
\hline
\end{tabular}

\section{Tingkat kesukaran}

Menurut Ali dan Ansori (2014:275) tingkat kesukaran suatu butir soal adalah proporsi dari subjek yang menjawab butir soal itu dengan benar, artinya makin besar proporsi, maka makin mudah soal, dan makin kecil proporsi makin sulit soal itu.

Untuk menentukan kesukaran suatu soal digunakan rumus sebagai berikut:

$$
T K=\frac{S_{A}+S_{B}}{n \text { maks }}
$$

(Jihad dan Haris ,2012:182)

\section{Keterangan:}

$\mathrm{TK}=$ Tingkat kesukaran

$\mathrm{S}_{\mathrm{A}} \quad=$ Jumlah skor kelompok atas

$\mathrm{S}_{\mathrm{B}} \quad$ = Jumlah skor kelompok bawah

$\mathrm{N} \quad=$ Jumlah siswa kelompok atas dan kelompok bawah

maks $=$ skor maksimal soal yang bersangkutan.

Tabel 3. Kriteria tingkat kesukaran

\begin{tabular}{|l|l|}
\hline Rentang & Kriteria \\
\hline $0,00 \leq \mathrm{TK} \leq 0,30$ & Sukar \\
\hline $0,31 \leq \mathrm{TK} \leq 0,70$ & Sedang \\
\hline $0,71 \leq \mathrm{TK} \leq 1,00$ & Mudah \\
\hline
\end{tabular}

Diadaptasi dari Jihad dan Haris ,2012:18

4. Daya pembeda

Oktra Okta Saktiawan, Della Maulidiya, Teddy Alfra Siagian 
Menurut (Arikunto, 2013:226). Daya pembeda soal adalah kemampuan sesuatu soal untuk berkemampuan rendah. Dengan daya pembeda dapat ditentukan soal yang baik dan tidak. Daya pembeda dapat dihitung dengan menggunakan rumus:

$$
D=\frac{B_{A}}{J_{A}}-\frac{B_{B}}{J_{B}}=P_{A}-P_{B}
$$

Keterangan :

$J \quad$ : jumlah peserta tes

$J_{A} \quad$ : banyaknya peserta kelompok atas

$J_{B} \quad$ : banyaknya peserta kelompok bawah

$B_{A}$ : banyaknya peserta kelompok atas yang menjawab soal itu dengan benar

$B_{B}$ : banyaknya peserta kelompok bawah yang menjawab soal itu dengan benar

$P_{A} \quad$ : proporsi peserta kelompok atas yang menjawab benar

$P_{B}$ : proporsi peserta kelompok bawah yang menjawab benar (Arikunto, 2013:228)

Tabel 4. Klasifikasi Daya Pembeda

\begin{tabular}{|c|l|}
\hline \multicolumn{1}{|l|}{ Daya } & Klasifikasi \\
\hline $0,00-0,20$ & Jelek \\
\hline $0,21-0,40$ & Cukup \\
\hline $0,41-0,70$ & Baik \\
\hline $0,71-1,00$ & Baik sekali \\
\hline Negatif & Tidak baik \\
\hline
\end{tabular}

(Arikunto,2013:232)

\section{e.2 Analisis Data}

1. Reduksi Data

Pada langkah reduksi data, pelaku penelitian melakukan seleksi data, memfokuskan data pada permasalahan yang dikaji, melakukan upaya penyederhanaan, melakukan abstraksi, dan melakukan transformasi. Dalam penelitian ini langkah reduksi data berupa: membedakan antara siswa yang pandai dengan siswa yang

Memeriksa hasil tes dengan memeriksa kesalahan apa saja yang dilakukan siswa dalam mengerjakan soal persamaan nilai mutlak linier satu variabel. .

2. Kesimpulan

Berdasarkan hasil analisis data, melalui langkah reduksi data dan penyajian data, langkah terakhir adalah menarik kesimpulan. Kesimpulan yang dibuat merupakan jawaban dari masalah penelitian. Kesimpulan yang dibuat berupa jenis-jenis kesalahan dan faktor penyebab kesalahan yang dilakukan siswa dalam menyelesaikan soal persamaan nilai mutlak linier satu variabel.

HASIL PEMBAHASAN

A. Hasil Penelitian

A.1 Pelaksanaan Uji Coba Instrumen Tes

Uji coba dilakukan bertujuan untuk mengetahui kelayakan dan memilih soal tes persamaan nilai mutlak linier satu variabel sebelum diberikan kepada kelas subjek. Soal disusun berdasarkan indikator pencapaian materi persamaan nilai mutlak linier satu variabel . Sebelum dilakukan uji coba, soal terlebih dahulu di uji validitas logis oleh validator. Uji coba instrumen tes dilakukan pada 32 orang murid kelas X MIA 5 SMA Negeri 3 Kota Bengkulu. Uji coba dilaksanakan pada hari Kamis, 17 November 2016 pukul 07.15 - 08.45 WIB.

Instrumen tes yang diberikan berjumlah 10 soal uraian materi bilangan pecahan. Siswa diberikan waktu 90 menit untuk menyelesaikan soal. Hasil pekerjaan siswa yang didapat dari soal uji coba selanjutnya di analisis dengan tahap-tahap uji instrumen berupa validitas, reliabilitas,

Oktra Okta Saktiawan, Della Maulidiya, Teddy Alfra Siagian

Jenis Kesalahan Siswa dalam Menyelesaikan Soal Persamaan Nilai Mutlak Linier Satu Variabel 
tingkat kesukaran, dan daya pembeda soal. Setelah melewati tahap-tahap pelaksanaan uji instrumen tersebut akan didapatkan soalsoal yang layak untuk diberikan kepada kelas subjek yang akan diteliti.

\section{A.2 Hasil Uji Coba}

Kriteria yang digunakan untuk validitas yaitu jika $r_{\text {hitung }} \geq r_{\text {tabel }}$ maka soal dianggap valid. Nilai $\mathrm{r}$ tabel dengan nilai signifikan $5 \%$ dan $\mathrm{n}=32$ adalah 0,349. Berdasarkan kriteria validitas maka soal yang dinyatakan valid adalah soal nomor $1,2,3,4,5,6,7$ dan 8 karena $r_{\text {hitung }} \geq 0,349$.

Hasil perhitungan reliabitas dari uji coba instrumen tes sebesar 0,66. Nilai tersebut berada pada rentang $0,40<r_{11} \leq$ 0,70 , yang berarti kriteria nilai reliabilitas soal-soal tersebut tergolong sedang. Hal ini menunjukkan bawah soal-soal tersebut reliabel dan dapat digunakan.

Hasil perhitungan pada tabel dapat diketahui bahwa tingkat kesukaran soal nomor 1,2,3,4,5 dan 6 memiliki kriteria sedang. Sedangkan soal nomor 7,8,9 dan 10 memiliki kriteria sukar. Soal yang digunakan dalam tes adalah soal yang memiliki kriteria mudah sedang dan sukar. Karena tingkat kesukaran soal nomor 1,2 dan 3 medekati mudah maka semua soal memenuhi kriteria.

Daya pembeda yang digunakan dalam penelitian ini yaitu soal yang memiliki daya pembeda $\geq 0,20$, dari tabel diatas terlihat soal nomor 9 dan nomor 10 memiliki daya pembeda yang buruk atau di bawah 0.20.

Dari penjelasan di atas dapat disimpulkan bahwa ke 10 butir soal uji coba telah melewati tahap-tahap uji instrumen. Soal yang akan digunakan adalah nomor 1,2,3,4,5,6,7 dan 8 karena memenuhi kriteria yang diperlukan.

\section{A.3 Pelaksanaan Tes}

Subjek dalam penelitian ini adalah kelas X MIA 3 SMA Negeri 3 Kota Bengkulu. Pemberian instrumen tes dilakukan pada hari Kamis, 24 November 2016 pukul 07.15 - 08.45 WIB. Waktu yang disediakan untuk menjawab 8 soal sama dengan waktu yang diberikan kepada kelas uji coba yaitu selama 90 menit.

Jumlah siswa yang mengikuti tes adalah 33 orang. Tes ini dilakukan bertujuan untuk menemukan kesalahan-kesalahan yang dilakukan oleh siswa dalam mengerjakan soal materi bilangan pecahan. Setelah hasil pekerjaan siswa didapat kemudian di koreksi dan kesalahankesalahan yang terjadi dapat dianalisis berdasarkan jenis-jenisnya.

\section{A.3.a Deskripsi Hasil Tes}

Berikut ini grafik rekapitulasi siswa menjawab soal berdasarkan soal dengan jawaban benar, soal dengan jawaban salah, dan soal yang tidak dijawab:

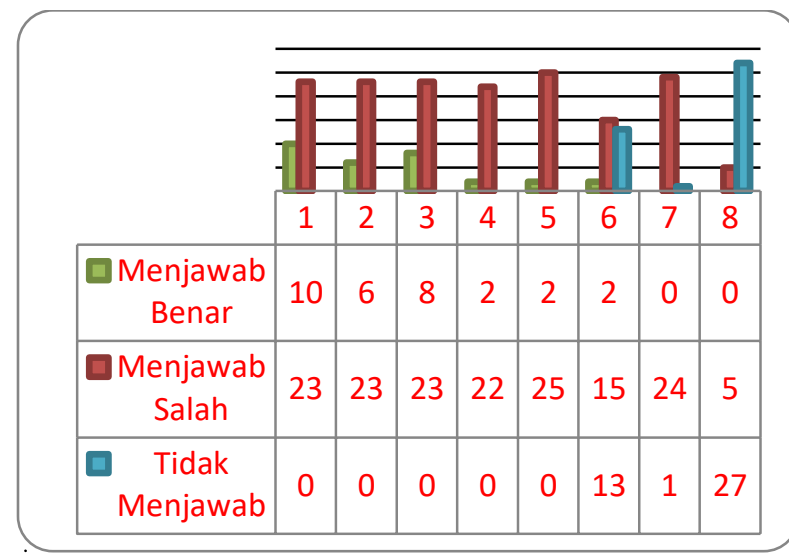

Gambar 4. 1 Grafik rekapitulasi siswa menjawab soal

Dari grafik terlihat jumlah siswa yang menjawab soal dengan benar, salah maupun tidak menjawab. Pada soal nomor 1 yang merupakan soal termudah ada 23 dari 33 siswa yang melakukan kesalahan dalam

Oktra Okta Saktiawan, Della Maulidiya, Teddy Alfra Siagian 
menyelesaikan soal. Hal ini menunjukkan masih banyak siswa yang belum paham materi persamaan nilai mutlak linier satu variabel. Pada grafik terlihat pula di soal nomor 5 terjadi kesalahan dalam menjawab tertinggi dilakukan oleh 25 siswa. Pada soal nomor 8 kesalahan dalam menjawab hanya dilakukan 5 orang namun banyak siswa yang tidak menuliskan jawaban ada 27 siswa. Hal ini menunjukkan siswa tidak mampu menyelesaikan soal yang diberikan.

Kesalahan dalam menjawab soal terbanyak ada pada soal nomor 5 dengan sub indikator menentukan nilai variabel dari persamaan mutlak a $|\mathrm{bx}-\mathrm{c}|+\mathrm{d}=$ e dengan $\mathrm{a}, \mathrm{b} \neq 0$ dan $\frac{e-d}{a} \geq 0$ yaitu 25 siswa. Dan yang melakukan kesalahan dalam menjawab soal paling sedikit ada pada soal nomor 8 dengan sub indikator menentukan himpunan penyelesaian dari persamaan mutlak $\frac{|a x+b|}{|x-c|}$ $=\mathrm{d}$ dengan $\mathrm{a} \neq 0$ dan $\mathrm{d} \geq 0$ yaitu 5 siswa namun pada soal nomor 8 ini ada banyak siswa yang tidak menuliskan jawaban.

\section{B. Pembahasan}

1. Penyebab kesalahan fakta adalah karena siswa tidak paham cara menuliskan jawaban HP.

2. Penyebab kesalahan konsep adalah karena siswa tidak memahami dengan benar konsep mengenai persamaan nilai mutlak linier satu variabel.

3. Penyebab kesalahan operasi adalah karena siswa salah dalam pengoperasian bilangan bulat negatif, bilangan pecahan, dan juga siswa salah dalam penyederhaan dari sebuah persamaan linier satu variabel

\section{Solusi Permasalahan}

Berikut solusi permasalahan yang dapat menjadi pertimbangan guru mata pelajaran matematika dalam rangka untuk memperbaiki hasil belajar siswa berdasarkan faktor penyebab terjadinya kesalahan:

1. Kesalahan Fakta

Penyebab siswa melakukan kesalahan fakta dalam menyelesaikan soal yang diberikan adalah siswa belum paham cara penulisan himpunan penyelesaian untuk persamaan nilai mutlak linier satu variabel yang benar penulisan himpunan penyelesaian.. Pada wawancara dengan siswa yang melakukan kesalahan diketahui bahwa salah satu faktornya adalah siswa ragu dalam penulisan himpunan penyelesaian yang benar.

2. Kesalahan Konsep

Penyebab siswa melakukan kesalahan konsep dalam menyelesaikan soal adalah siswa belum memahami konsep persamaan nilai mutlak linier satu variabel dengan benar contohnya siswa yang masih menuliskan persamaan nilai mutlak yang bernilai negatif. Pada wawancara dengan siswa yang melakukan kesalahan diketahui bahwa faktornya adalah siswa tidak memahami konsep nilai mutlak dengan benar.

3. Kesalahan Operasi

Penyebab siswa melakukan kesalahan operasi dalam menyelesaikan soal adalah karena siswa belum paham prosedur pengerjaan soal, dan siswa juga belum memahami materi prasyarat yaitu persamaan linier satu variabel dengan baik dan siswa tidak teliti saat meyelesaikan soal.

Berdasarkan kesalahan di atas solusi pemecahan masalahnya adalah

1. Guru perlu memastikan siswa telah menguasai materi prasyarat yaitu persamaan linier satu variabel.

2. Guru perlu memastikan siswa memahami konsep persamaan nilai mutlak linier satu variabel dengan benar.

Oktra Okta Saktiawan, Della Maulidiya, Teddy Alfra Siagian

Jenis Kesalahan Siswa dalam Menyelesaikan Soal Persamaan Nilai Mutlak Linier Satu Variabel 
3. Guru perlu menekankan langkah pengerjaan saat mengerjakan soal persamaan nilai mutlak linier satu variabel yang belum dalam bentuk umum.

\section{B. SIMPULAN DAN SARAN}

\section{D.1 Simpulan}

Kesalahan-kesalahan yang dilakukan siswa dalam menyelesaikan soal Persamaan Nilai Mutlak Linier Satu Variabel di kelas X MIA 3 SMA Negeri 3 Kota Bengkulu yang berjumlah 33 siswa adalah :

1. Sebanyak 26 siswa melakukan kesalahan pada indikator 1 yaitu dalam menyelesaikan persamaan mutlak $|\mathrm{x}-\mathrm{a}|=\mathrm{b}$ dan $\left|\mathrm{x}-\frac{a}{b}\right|=\frac{c}{d}$. Kesalahan yang dilakukan berupa 22 siswa melakukan kesalahan konsep dan 7 siswa melakukan kesalahan operasi.

2. Pada indikator Sebanyak 26 siswa melakukan kesalahan dalam menyelesaikan persamaan mutlak |ax $+\mathrm{b} \mid=\mathrm{c}$ dan $\left|\frac{a}{b} \mathrm{x}-\mathrm{c}\right|=\mathrm{d}$. Kesalahan yang dilakukan berupa 21 siswa melakukan kesalahan konsep dan 12 siswa melakukan kesalahan operasi.

3. Pada indikator 3 sebanyak 29 siswa melakukan kesalahan dalam menyelesaikan persamaan mutlak a | $\mathrm{bx}-\mathrm{c} \mid+\mathrm{d}=\mathrm{e}$ dan $\mathrm{a}\left|\frac{b}{c} \mathrm{x}-\frac{d}{e}\right|+\mathrm{f}=\mathrm{g}$. Kesalahan yang dilakukan berupa 27 siswa melakukan kesalahan konsep
4. Guru perlu menekankan syarat saat mengerjakan soal persamaan nilai mutlak linier satu variabel dalam bentuk rasional.

dan 13 siswa melakukan kesalahan operasi.

4. Pada indikator 4 Sebanyak 24 siswa melakukan kesalahan dalam menyelesaikan persamaan mutlak |ax $-\mathrm{b}|=| \mathrm{c}-\mathrm{x} \mid \operatorname{dan} \frac{|a x+b|}{|x-c|}=\mathrm{d}$. Kesalahan yang dilakukan berupa 9 siswa melakukan kesalahan fakta dan 14 siswa melakukan kesalahan konsep dan 16 melakukan kesalahan operasi.

\section{A. Saran}

Beberapa kesimpulan yang dapat penulis sampaikan adalah sebagai berikut :

1. Bagi para peneliti yang akan meneliti materi yang sama hendaknya meneliti lagi faktor penyebab siswa melakukan kesalahan dalam menyelesaikan soal dari faktor lainnya seperti faktor eksternal siswa.

2. Bagi para guru hendaknya menggunakan alat peraga sehingga siswa dapat lebih mudah memahami materi atau konsep persamaan nilai mutlak linier satu variabel yang diajarkan dan tidak salah dalam memahaminya. 


\section{DAFTAR PUSTAKA}

Arikunto, S. (2013). Dasar-dasar Evaluasi Pendidikan. Jakarta: PT. Bumi Aksara.

Arikunto, S. (2010). Prosedur Penelitian Suatu Pendekatan Praktik. Jakarta: Rineka Cipta.

Dimyati, \& Mudjiono. (1994). Belajar dan Pembelajaran. Jakarta: Direktorat Jendral Pendidikan Tinggi Departemen Pendidikan dan Kebudayaan.

Hamzah, Ali \& Muhlisrarini. (2014). Perencanaan dan Strategi Pembelajaran Matematika. Jakarta: PT. Rajagrafindo Persada

Jihad, A., \& Haris, A. (2012). Evaluasi Pembelajaran. Yogyakarta: Multi Pressindo.

Adi K, Dwi. (2001). KAMUS PRAKTIS BAHASA INDONESIA. Surabaya : Fajar Mulya.
Mardapi, Djemari. (2012). Pengukuran, Penilaian, dan Evaluasi Pendidikan. Yogyakarta: Nuha Medika

Slameto. (2003). Belajar dan Faktor-Faktor yang Mempengaruhinya. Jakarta : Rineka Cipta.

Soedjadi, R. (2000). Kiat Pendidikan Matematika di Indonesia. Jakarta: Direktorat Jendral Pendidikan Tinggi Departemen Pendidikan Nasional.

Sudijono, A. (2011). Pengantar Statistik Pendidikan. Jakarta: PT. Rajagrafindo Persada. Sukino. (2014). Matematika untuk SMA/MA Kelas $X$. Jakarta : ERLANGGA.

Suwarto. (2013). Pengembangan Tes Diagnostik Dalam Pembelajaran. Yogyakarta : Pustaka Pelajar. 